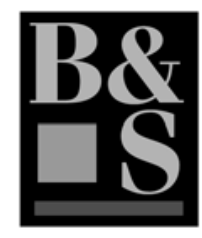

\title{
The Body We Care For: Figures of Anthropo-zoo-genesis
}

\section{VINCIANE DESPRET}

What really exists is not things made but things in the making. (William James, 1958a: 263)

One morning in September 1904, in Berlin, 13 gentlemen belonging to different spheres of social life came together in a courtyard in Griebenow Street. They had never worked together before. Some of them had never even met. Professor Stumpf was the director of the Institute of Psychology; Dr Heck was the director of the local zoo; Mr Hahn was a teacher at the Municipal school; Dr Miessner was a veterinarian; one of the gentlemen was a retired army officer; another was an aristocrat; Paul Busch was simply a circus-manager. The courtyard they were working in belonged to a $\mathrm{Mr}$ von Osten, former teacher of mathematics at the Berlin Gymnasium. This gentleman was also present at the meeting. Throughout the day, all these persons addressed questions to one of the famous pupils of this time, Mr von Osten's pupil, Hans. They asked him to solve multiplication and division problems, and to extract square roots. Hans was also requested to spell words and, among other tests, to discriminate between colours or tones and intervals in music. Not only did Hans answer with good will, but he also answered most of the questions correctly. He was around 4 years old. However,

Body E Society (C) 2004 SAGE Publications (London, Thousand Oaks and New Delhi), Vol. 10(2-3): 111-134

DOI: $10.1177 / 1357034 X 04042938$ 
the most astonishing fact was not his young age. Hans answered questions by tapping his right foot on the floor. Hans was a horse.

How could a horse do that? This was the issue these gentlemen were called upon to investigate. This story had actually begun a few months earlier, when a local newspaper published an article relating the marvellous feats of the horse. Day after day, an increasing number of curious visitors had been coming to the courtyard to observe the horse and his master at work. Scientists and famous people followed. Thus emerged one of the most intense controversies of that time: for some of the people who saw Hans there were no doubts about the accomplishments of the horse, while for others, the story was nothing more than a tale of credulity founded on a fraud. Mr von Osten, offended by the suggestions of fraud, appealed to the board of education in Berlin. A committee was therefore formed, consisting of the 13 gentlemen mentioned. After hours of observation, they all agreed. No signals could be perceived; no tricks like those that are used in the circus with trained animals could be noticed. But the best evidence was that Hans could answer these gentlemen in his master's absence!

Was Hans a genius? Some thought so. Or was he, as some suggested, a telepathist who could read the mind of his questioner? Professor Stumpf, who led the commission, was careful when he wrote his report: no signals or tricks 'which are at present familiar' seemed to be involved (Pfungst, 1998). He insisted that this did not mean that Hans could be credited with having conceptual intelligence. This case, Stumpf concluded, is worthy of serious and incisive investigations. In other words, more research should be done.

One of Stumpf's assistants at the university, the psychologist Oskar Pfungst, is therefore enrolled to solve the mystery. He goes to the courtyard where Hans lives and performs for the public, and poses questions to the bright horse. Clever Hans gives him correct answers. However, Pfungst does not credit Hans with conceptual intelligence, nor does he believe in some paranormal phenomenon. He is convinced by the results obtained by Stumpf and the other witnesses: there are no tricks involved (otherwise the horse wouldn't answer in his master's absence). The solution to the enigma must be found elsewhere. Stumpf concludes in his report that he too cannot notice any signals that are 'at present familiar'. This is then the solution: the horse must be reading cues. These are cues that humans cannot perceive and, moreover, the cues are given to him unintentionally! And Pfungst will find them.

The psychologist enlists some of the gentlemen who have been working with the horse and sets to work. He carefully observes the questioners putting mathematical problems to Hans: no signals seem to be at work. However, Pfungst still believes these signals are produced. How to find evidence of their existence? His 
hypothesis is simple: if the questioner does not know the answer to the question he asks, he won't be able to give these supposed signals, and the horse will fail to answer correctly, which will prove that unintentional signals are actually at work. Mr von Osten asks Hans to repeat a number to another gentleman and leaves the courtyard. The latter, who did not hear the number chosen, comes in and asks Hans to repeat it. Hans fails. If the questioner does not know the answer, the horse cannot find it. There are signals, then. Pfungst may now begin to try to find them. And he will. For hours and hours, he observes, experiments, puts different hypotheses to the test: what happens if Hans cannot hear the question? The horse still counts. What happens if he cannot see the face of the questioner? Hans still counts. What happens if Hans cannot see the body of his questioner? He fails. The body is involved: Hans can read human bodies. Carefully comparing the different questioners, all the movements each one produces when he asks the question and waits for the final answer, and also the questioners who did not succeed in leading Hans to success, Pfungst ends up with the key to the enigma. Unintentional minimal movements (so minimal that they had not been perceived until now) are performed by each of the humans for whom Hans had successfully answered the questions. As soon as the questioner gives a problem to the horse, he involuntarily bends his head and trunk slightly forward (to look at the foot that was supposed to begin the tapping). The tension mounts; the mounting tension results in the questioner maintaining the same position. But as soon as the desired number of taps is given, the questioner releases his tension, and involuntarily makes a slight upward jerk of the head and the trunk. The horse just keeps his right foot on the floor. Each of the questioners observed by Pfungst produced these movements. And no one among them knew they were doing so, no one among them noticed that their bodies were talking to the horse, telling him when to begin and when to stop. Each of them, except the horse, was ignorant of this astonishing phenomenon: their bodies were talking and moving against their will, outside the frame of their consciousness.

\section{Clever Bodies}

The most interesting aspect of this story is the way Pfungst decided to construct the problem. Yes, it was a beautiful case of influence, but it was moreover a wonderful opportunity to explore a fascinating question. Indeed, the horse could not count, but he could do something more interesting: not only could he read bodies, but he could make human bodies be moved and be affected, and move and affect other beings and perform things without their owners' knowledge. And this could be experimentally studied. Hans could become a living apparatus 
that enabled the exploration of very complicated links between consciousness, affects and bodies. ${ }^{1}$ Hans could play the role of a device that induced new articulations between consciousness, affects, muscles, will, events 'at the fringe' of consciousness (Pfungst, 1998: 203); he could be a device that, furthermore, made these articulations visible. Hans, in other words, could become a device that enabled humans to learn more about their bodies and their affects. Hans embodied the chance to explore other ways by which human and non-human bodies become more sensitive to each other.

Pfungst was so interested in this new access that he even created a typology of human bodies according to their capacity for being affected and for being able to affect. Why did only a few persons receive responses regularly from Hans, whereas the majority of people were favoured only occasionally? The most successful among the subjects who questioned Hans, he wrote, have ability and tact in dealing with animals. They have the power of intense concentration in expectation. They show a great facility for motor discharges or are gesturally inclined:

. . . during infancy we are trained to keep all of our voluntary muscles under a certain measure of control. During the state of concentration (while working with Hans), this control is relaxed, and our musculature becomes the instrument for the play of non-voluntary impulses. (Pfungst, 1998: 204)

Long dealings with very abstract thoughts, for example, weaken this capacity. Talented bodies also have the power to distribute the tension, to sustain it long enough and to relax it at the right moment. In sum, the questioner should embody his will of success (a sort of 'you ought to' addressed to Hans) while ignoring it. And this embodiment may be qualified by two other terms: trust and interest. Trust and interest because the ones who succeeded with Hans did so as long as they were confident of success: 'when they did not anticipate success, they failed' (1998: 161).

Hans's greatest feat, Pfungst explains, was to show an extremely keen reaction to every movement of the questioner. Horses, Pfungst adds, are generally excellent muscle-readers: they read the mind of their rider through the pressure of the bit. We know that in the case of perfectly trained horses, the rider's mere thought of the movement that he expects the horse to make is seemingly sufficient to cause the animal to make it. Pfungst quotes Tolstoy's story of the race opposing Count Wronskij, riding Frou-Frou and Machotin on Gladiator (from Anna Karenina):

At the very moment when Wronskij thought it was time to overtake Machotin, Frou-Frou, divining her master's thought, increased her pace considerably and without any incitement on his part. She began to come nearer to Gladiator from the near side, which was the most 
favorable. But Machotin would not give up. Wronskij was just considering that he might get past by making the larger circuit on the off-side, when Frou-Frou already changed direction and began to pass Gladiator on that side. (1998: 184)

Following Tolstoy, we may suggest that Hans's greatest talent was to be able to switch from one sense (the sense of kinaesthesia) to another: the visual. Talented horses generally read through their skin and their muscles; Hans could read all these signals visually. Hans was truly talented.

Was reading muscles and doing so visually his only actual talent? We should not leap to a conclusion. Of course, we are not aiming to rescue his mathematical abilities; what Hans seems to be able to do is actually much more interesting. Jean-Claude Barrey, a French ethologist who has been working with horses for years, suggests construing the case in another manner (interview, Aug. 2003). Rereading Tolstoy's beautiful descriptions, he notes something very important. What Tolstoy described is nowadays known as the 'isopraxis' phenomenon. Unintentional movements of the rider occur, as Tolstoy suggested, when the rider thinks about the movements the horse should perform. The horse feels them and, simultaneously, reproduces them. A careful analysis of these unintentional movements made by the human body has shown that these movements, in fact, are exactly the same as the ones the horse performs. The human's right hand imitates (and anticipates) what the horse's right front leg will do, the bottom of the back of the rider makes a jerk which is exactly the movement the horse will do to begin to canter, and so on. In other words, according to Barrey, talented riders behave and move like horses. They have learned to act in a horse-like fashion, which may explain how horses may be so well attuned to their humans, and how mere thought from one may simultaneously induce the other to move. Human bodies have been transformed by and into a horse's body.

Who influences and who is influenced, in this story, are questions that can no longer receive a clear answer. Both, human and horse, are cause and effect of each other's movements. Both induce and are induced, affect and are affected. Both embody each other's mind. Shouldn't we therefore suggest the same for Hans and his questioners? If we can see, according to Pfungst's hypothesis, how human bodies influence the horse's answer through his peculiar sensitivity and talent, shouldn't we also imagine the converse situation: the horse has taught the humans, without their knowledge, the right gestures to (involuntarily) perform. Pfungst seems to hesitate. First, he assumes that most of the gestures performed are 'natural expressive movements'. But there is one gesture that seems not to obey this rule and might support our hypothesis, which could allow for a fairer distribution of 'influence'. When Pfungst asks his questioners to think about the answer 'null' or 'zero', he notes that the minimal gesture is not the same as when 
they are in the horse's presence. When they concentrate on the thought 'null' or 'zero', for Pfungst, the minimal gesture is a slight ellipse with the head; when they ask the horse, it is a shaking of the head that is observed, which is exactly the movement used by the horse to answer. How could it happen that humans replace their own spontaneous movements with that of the horse, unless we assume that Hans taught them the gestures he needed? Hans has made them move otherwise, he changed the habits of their bodies and made them talk another language. He taught them how to be affected differently in order to affect differently.

Another characteristic should lead us to suspect that Hans could actively 'influence' his questioner. Pfungst, in the beginning of his research, observed that some questioners would initially receive good answers from the horse, but would fail in the trials that followed. By contrast, others needed what he called 'some practice' but performed better and better after a while. What could this 'practice' mean? How to explain that they failed during the first trials and finally succeeded? Is it only human practice, as Pfungst assumes? We could suggest quite a different story: they had to learn to which cues Hans was sensitive, without knowing that they were learning. How could this happen? The practice was not on the questioner's side only: Hans was teaching them what made him move. Hans the horse was as much leading them as the humans were leading him. Their human bodies were not only sensitive to their own desire to make the horse succeed, they were also translating the horse's desire to help them to lead him successfully. Let us not miss that last point: Hans wouldn't have done so well if he had not been interested in the game, sometimes for different reasons than some of the humans. The hypothesis of him teaching humans how to be moved testifies to his 'preference for agreement', ${ }^{2}$ in that he attempted to align his action with what was expected of him. In some ways, trust and interest, even for very different stakes, could be shared. In addition to the human bodies involved who were deeply engaged and interested, Hans's feats also testify to his capacity to be actively engaged in the game proposed, to give intense attention to minimal gestures expressing human desires, expectations and affects, and to respond to them in a remarkable way.

\section{The Hans Legacy: The Bright and the Dull Rats}

No matter how interesting this research was, this is not the way Hans's story has been transmitted. Clever Hans has become famous in the history of psychology, but for quite different reasons: today, when the horse's story is called upon, it involves very different stakes. Influence, which was for Pfungst the best way to 
study experimentally how bodies can 'articulate' differently (Latour, 2000), became, for modern psychologists, a menace they strove to eradicate. Whenever Hans, the bright horse, is requested to testify about someone else, be it talking apes or intelligent ravens, I will argue, his testimony is always called upon to impoverish the range of explanations.

Rosenthal's experiment illustrates this. About 60 years after the Clever Hans episode, Rosenthal, a psychologist, decided to put the case to the test. The experiment is quite simple: Rosenthal (1966) asks students enrolled in a laboratory course in experimental psychology to repeat the work on Maze-bright and Mazedull rats, work done years ago by a famous experimental psychologist from Berkeley, Tryon. Many studies, Rosenthal explains to the students, have shown that continuous inbreeding of rats that do well in a maze has led to successive generations of rats that do considerably better than 'normal' rats; and that continuous inbreeding of rats that do badly in a maze has led to successive generations of rats that do considerably worse than 'normal' rats. Each student is assigned a group of rats to work with, some of them working with 'bright' rats, while the others work with 'dull' animals. Rosenthal tells his students that those who will be working with bright rats should expect to find evidence of good performances, while those who will be working with dull ones should expect to find little evidence of learning in their rats. The 'Berkeley rats', as he called them to his students, were then distributed to the students, at the beginning of the experiment.

The students tested the rats, and confirmed the effects of selection: the bright ones produced good performances in learning while the dull ones performed rather poorly.

Since every rat did what was expected, what does Rosenthal's experiment show us? These are exactly the terms in which the problem can be defined: each of these rats did exactly what was expected from him, and nothing else! All these 65 little rats, in fact, were naïve rats. They did not actually come from Berkeley; they were not the result of years of cautious inbreeding, and their great-greatgreat- . . grandfathers had never heard of Tryon. Although the students had been told that the rats were different, they were simply naive albino rats, randomly labelled 'bright' or 'dull'. If I dare make the comparison, naïve students had studied naive rats.

Rosenthal, in fact, had only one aim (which he had at first hidden from his students): he explains later that he had sought to find in the experiment the little things that produce differences - the little things that 'affect the subjects to respond differently than they would if the experimenter had been literally an automaton' (1966: 119). ${ }^{3}$ These words are not used by chance, and the reference 
is meaningful. What does the idea of an automaton mean for Rosenthal? Let us refer to the etymology: the auto-maton is the one who is moved by itself, and only by itself, that is the one who will not be moved, put into motion by others. In sum, it is the one who will not be affected, and therefore who will not affect, his object of study: an indifferent autonomous experimenter collecting indifferent data. As a matter of fact, the study of these 'little differences' that Rosenthal wanted to spot, these differences that affect the subject making him or her respond differently, was a marvellous idea. But Rosenthal's original idea had not been to explore a world enriched and created by these differences; it had been to mark them off as parasitic supplements that seriously contaminate the purity of the experiment. What is at stake is simple: the experimental device is built in order to show and to elucidate how experimenters produce bias, in order to eradicate this bias, or at least, to neutralize its effects.

The question, however, remains: how did the students obtain results that confirmed their expectations, or, in Rosenthal's words, how did all these differences end up producing biased results? Rosenthal cannot give us clear answers. Certainly, he asserts the results are not due to intentional or other errors, each student being under close supervision. Rosenthal suggests that some emotional factors played a role: the bright rats were handled more gently, treated with more care, probably encouraged more. Moreover, the students had to fill in a questionnaire, after the test, and they had to characterize their relation with their rats, and how they felt about the experiment. The experimenters who worked with bright rats judged their rats to be more likable and more pleasant than did the experimenters running dull rats.

We can also, as Rosenthal suggests, consider the problem as a problem of power, and we may ask what would happen to a student whose results contradicted what he was supposed to find. Rosenthal has been cautious about that, and each student was told, before the experiment, that there would be no external sanction; the performances of the rats wouldn't affect the performances (the grades) of the students. However, if the question is raised in these terms, in terms of the power of the experimenter, it seems to me that it evades the real issue: the real power of science is not so much power as authority. Authority has to be understood here in the sense given by Gregory Bateson: a person is said to have authority when anyone who is under the influence of that authority does everything possible to make whatever this person says be true.

Here we may suggest that Rosenthal missed the reflexive question. Indeed, if we accept this definition of authority, is this not exactly what happened in this experiment? Students did everything possible, everything they could, to make what Rosenthal said be true, because it mattered for them that it was. The 
Berkeley rat is a prestigious rat, from a prestigious university; Rosenthal is a famous professor, he is an authority. The relationship between him and his students has to be construed as a relation characterized by authority. Of course, we do not deny that the rats were called upon to perform according to the expectations; but shouldn't we say also that the students themselves acted beautifully to fulfil Rosenthal's expectations? Should we not admit that the rats fulfilled more expectations than just those of the students? They all played the game as best they could, just as Hans and his questioners did. They all exhibited this 'preference for agreement'; their will to achieve what was expected from each of them at different levels.

While Rosenthal complained about experiments, his own successfully provided a reproduction of the black box he had wanted to open, black-boxing together rats, students and himself. Commenting on his experiment, he argued that the bright or the dull rats are not bright or dull in 'reality', they are produced with such properties in a 'pseudo-reality', the unreal field of by-products of beliefs, expectations and illusions. Thereby, Rosenthal split reality and distinguished between what was real and what was the effect of influence, interest, affects: over there, that is Reality per se, the collection of data by enthusiastic (and 'automated') scientists; here, this is subjectivity, construction, expectations, illusions.

What do we criticize Rosenthal for? We blame him for not realizing that the students, just like the rats, are not in a 'real reality', as long as they are activated by Rosenthal's beliefs.

However, note the following: if we follow my criticism we are making even more distinctions than Rosenthal made! With Rosenthal, there is a distinction between the reality of the world (the bright and dull rats should be there but they are not; the student is there, and really deceived; both naivetés are guarantees of the real world) and the 'reality' of the subject (i.e. the false reality produced by beliefs, subjectivity, artifacts). With my criticism, neither the rats nor the students are in the reality of the world, as both are in the reality of the subject (rats being produced by students' expectations, students being produced by Rosenthal's expectations).

What is left? Almost nothing, I am afraid. Rosenthal duplicated the ontology (one false reality for the rat, one real reality for the student). We did not do any better. In fact, we did worse: we actually emptied ontology. There is no more reality; our ironic distribution has completely cleared it away. And we may wait, now, for someone to come to talk to us about our own beliefs, about Rosenthal fulfilling our expectations. How can we give reality its due?

To change this situation ${ }^{4}$ we may reconsider both the concept of authority and 
the parallelism between Rosenthal's and the students' expectations. What does Rosenthal do with his authority? The word's etymology suggests to us the answer: he not only allows, but he also authorizes. Shouldn't we consider that what Rosenthal is doing, what his expectations and authority are doing, is to authorize a student to become a competent experimenter (not exactly in Rosenthal's sense), ${ }^{5}$ to become an experimenter able to make an intelligent rat exist (let us take the bright cases for our purpose, the others are just there to provide a contrast and to invite us to think about what it means 'not to propose' to the animal to give the best of what may be expected). Therefore, we can acknowledge that the student-experimenter, while fulfilling Rosenthal's expectations, is also becoming a good experimenter in 'real reality', producing good realities; producing real rats that become intelligent rats. The expectations of a good experimenter have authorized the rat to become competent; the authority of Rosenthal allows the student to be entitled to produce competent rats. ${ }^{6}$

If we define expectations in terms of 'who authorizes', we can see that everything is shifting, articulating many more things, giving chances to many more entities to belong to the real world. If Rosenthal authorized his students to become fine experimenters, able to bring into existence intelligent rats, shouldn't we then acknowledge the same role for the rat? Doesn't it, in fulfilling the expectations of his student-experimenter, authorize the latter to become a competent experimenter able to create an intelligent rat? Exactly as we, in redistributing the influence more fairly between Hans and his questioners, could construe the situation as a situation in which Hans could enable the humans questioning him to gain a body that does more things, that feels other events, and that is more and more able to lead him.

Instead of a clear-cut distribution that dramatically and paradoxically disorganizes reality, we now have an undetermined distribution that brings much more order. And, surprisingly enough, for such an undetermined distribution where Rosenthal authorizes a student to authorize a rat and where a rat authorizes a student - we find, in a sense, the hypothesis in Rosenthal's text itself. ${ }^{7}$ At one moment, we see Rosenthal suddenly possessed with perplexity: was it not the case that the rats have, in some way or another, influenced the student?

Should we, then, regard the experimenter's behavior toward his subject as antecedents or as consequents of the subject's performance? Perhaps it makes most sense to regard experimenters' behavior as both. (1966: 177)

Let us pay attention to this new version. It allows us to give an active role to the rat. It allows us to give words back to the rat! This version authorizes us to authorize Rosenthal, the students, the rats; it authorizes us to be authorized by 
them: it allows us to transform a cascade of bad faith into its opposite, into a cascade of new existences raising new questions, a cascade of trust.

If with that question, Rosenthal seems to give a chance to the rat, we should mention that, in the next sentence, he changes his mind. The reasons for this quickly appear: Rosenthal suddenly recalls the famous Clever Hans case. 'Influence' as the eternal source of error returns front stage. Why does Rosenthal suddenly seem to change his mind and come out with that story? The reason is clear: because he cannot accept transformations. He adopts the most impoverished version of Hans's marvellous story in order to remind us that the rats, finally, could not be real (of course, we all agree, Hans could not count). These rats could not be affected nor could they affect their students in the process of gaining reality. And convincing his students of that proved to be the most difficult thing! Because after the experiment, these students, even after they had been made aware of the real aim of the study, continued to believe in their rat. Rosenthal comments, rather ironically, that the reaction of some students was:

. . . a sudden increase in sophistication about sampling theory. . . . Many of these experimenters pointed out that, of course, by random sampling, the 2 groups of rats would not differ on the average. However, they continued, under random sampling, some of the 'dull' rats would really be dull by chance, and that their animal was a perfect example of such a phenomenon.

Caught between what their rats have taught them (we did perform as we did!) and what Rosenthal wanted to prove, the only way to solve the double bind was to believe that a differently able rat really existed before the experiment!

How could they simultaneously trust their rats and their professor if science is defined as a process of revealing pre-existing reality instead of creating a becoming? How could they give faith to both?

Indeed, the whole matter is a matter of faith, of trust, and this is the way I suggest we should construe the role of expectations, the role of authority, the role of events that authorize and make things become. It is because the students could (in the best cases, of course) trust their rats, because they had faith in what the rats were able to perform, and in turn, because they could trust that the rats were going to enable them to be good experimenters, that the experience worked. Students who succeeded in transforming their rats into bright rats won their trust; as much as these bright rats were winning the students' trust. We may also consider that it is because the students had faith in Rosenthal's propositions that they could fulfil his expectations, and take these expectations as their own.

Certainly, trust is rather problematic in an experiment based on deception, and this is probably a remaining difficulty. But it is not difficult to imagine that even if Rosenthal had not lied, even if he had proposed to the students to take part in 
the experiment 'as if' the rats were bright or dull, it would have worked. Anyhow, we may say that the students were reliable as long as they could fit in with Rosenthal's expectations. And we may also admit that Rosenthal would not have set the whole thing up if he had not trusted the capacity of the students to fulfil his expectations, that is, their capacity to make rats exist differently. The students, and this is still clearer, put their trust in their rats, emotional trust, trust that is conveyed in gestures, in students' bodies, in all these rats' bodies that were manipulated, caressed, handled, fed and encouraged: the students succeeded in attuning their rats to their beliefs. And this is the most interesting fact of this experiment - a fact that is rather hard to grasp, however - these beliefs brought into existence new identities for the students and for the rats. These emotional relations, made of expectations, faith, belief, trust, which link each rat to each student, disclose the very essence of the practice: this is a practice of domestication. As long as this practice proposes new ways to behave, new identities, it transforms both the scientist and the rat. Both the student and the rat transform the practice that articulates them into what we may call an 'anthropo-zoo-genetic practice', a practice that constructs animal and human. ${ }^{8}$ The rat proposes to the student, while the student proposes to the rat, a new manner of becoming together, which provides new identities: rats giving to students the chance of 'being a good experimenter', students giving to their rats a chance to add new meanings to 'being-with-a-human', a chance to disclose new forms of 'being together'. Wasn't that what we learned with Hans? On the one hand, the clever horse gave to his human questioners the chance of 'becoming with a horse', performing a body that a horse can read, acquiring a horse-sensitivity. On the other, humans domesticating horses offer them a new identity: being a horsewith-human.

'Trust', writes Isabelle Stengers, 'is one of the many names for love, and you can never be indifferent to the trust you inspire." This trust that links together students and rats, this trust that produces opportunities and domestication, may now allow us to redefine belief. If you define a belief in terms of 'what it is', you always run the risk of ending up with notions of error, deception: the world is full of people believing that others (wrongly and passively) believe. By contrast, if you define 'beliefs', in a pragmatic way, not in terms of 'what they are', but of 'what they make', the scene has completely changed: it becomes a site full of new active entities that articulate differently. This will be the pragmatic definition that will lead our work: a belief is what makes entities 'available' to events. It is because the students believed that their rats could be bright that both of them became available to the transformation of their identities: being good and bright rats on the one hand; being careful (in the most literal sense) and accomplished 
experimenters on the other. The articulations may even be more complicated: the bright rats were, in their 'becoming bright', making each of their students available to their becoming scientists; also, the students were making their rats available to create new relations with them. Indeed, the definition does not come down in favour of a 'who' or a 'what' that is made available to the happening. Leaving it undetermined or hesitant allows many more entities to be active. Indeed, as long as we stay in the middle realm, we may disclose how an affected and affecting student makes himself available to the 'becoming' of the rat, as well as how the rat makes itself available to the 'becoming' of the student.

However, to make this definition practical, to articulate it with trust, we should point out a distinction between 'being available' and 'being docile'. We said that the student was, as much as the rat, available to an event they created together. But may we say the same about the rhesus monkey that Harlow separated from his mother and peers, in order to measure the effects of an apparatus designed to create despair (also in order to make Harlow feel entitled to talk about love)? ${ }^{10}$ Harlow's only concern is to obtain monkeys that are docile in terms of the experiment. How may we assume that a setting is designed to perform docility rather than availability? I think we can draw the difference from the possibility of 'resistance'11 that each of the settings offers to the one it addresses. Of course, the students 'expect' something from their rats; but each of these rats may always resist what is said about $\mathrm{him} / \mathrm{her}$; what is expected from him/her. To fulfil expectations, to be available to others' beliefs or concern is not to obey these expectations or beliefs. I find good evidence of it in this story.

We are still in Rosenthal's experiment. A student experimenter comments on his work at the end of the process: 'Our rat, number $\mathrm{X}$, was in my opinion extremely dull. This was especially evident during training for discrimination' (Rosenthal, 1966: 176). However, as surprising as it may be, after analysing the data this rat appeared to be one of the best of the dull category, even on a discrimination test, and its results were very close to the bright category. It makes sense to think that this rat responded, but in its own way, to the student's expectations of it, and that it cannot be said to have obeyed it. Of course, the prophecy was not fulfilled in that the rat resisted nicely; but this does not mean that both the rat and its experimenter were not, in a subtle way, available to something else that shows close links with trust. This appears when we read what the student adds:

. . . perhaps it might have been discouraging (to work with such a dull rat) but it was not. In fact, our rat had the 'honor' of being the dullest in all the sections. I think that this may have kept our spirits up because of the interest . . . in our rat. $(1966: 176)^{12}$ 
In fact, the rat did not obey the expectations of the student (it was supposed to be dull), but it was available to some more subtle expectations, the expectations of someone who cares, of someone who trusts, moreover, of someone who was interested, someone it interests (inter-esse, to make a link). And this dull rat became, in some strange way, the one that gives and that has honour, the one that keeps the spirits up; it disclosed an interested experimenter bringing into existence a very interesting rat. Therefore, even if the rat did not fall in with expectations (it resisted rather nicely in being one of the best of the dull ones), it was, however, available for some of them: the expectations of an interested student asking for an interesting rat.

By contrast, we may say that the rhesus monkey literally tortured by Harlow could hardly find means to resist the apparatus and the questions that are addressed to him/her. One of the ways to resist an apparatus is to lead the experimenter to transform his/her questions into new ones that are the appropriate questions to ask that specific individual. In other words, an apparatus that does not have a stake in docility is an apparatus that is designed to give the opportunity to the 'subject' of the experiment to show what are the most interesting questions to address to him; what are the questions that make him/her the most articulate. By contrast, as we see, each of Harlow's rhesus monkeys is articulated by the apparatus in such a way that there is no one to raise the question of the 'point of view', the question of what 'makes sense' for a rhesus monkey, the question of how the experiment itself constructs a 'monkey-without-anyone'. Thereby, Harlow cannot take into account the question of relevance, the question that asks what are the good questions that offer an interesting becoming for those to whom the question is addressed, that is, the question that construes and constructs signs that 'make a world' for the animal. ${ }^{13}$

The contrast between a scientist who relies on the availability of both the apparatus and the animal, and a scientist who requires docility (this scientist being himself docile to the perceived prerequisites of science) may be translated along another contrast: the contrast between the manner of addressing oneself to the system, on the one hand as a care-taker, as somebody interested in its possible becoming, and on the other hand, as a judge or a master. In the first case, the animal is what articulates the system, in the other, it is the system that articulates the animal, which just has to show how it obeys laws. ${ }^{14}$ We find evidence of this contrast when we observe how an animal may resist what is expected of it. How can a rhesus monkey resist Harlow's experiment? By showing despair? Of course not, that is exactly what is expected of it. By becoming happy? I would not bet on it.

The definition of beliefs as 'availability' to the events, by contrast with the 
'docility' on which some practices rely, cannot be reduced to sentimental concerns or moral issues. It is first of all a matter of raising more interesting questions that enable more articulated answers, and therefore more articulated identities. It is an epistemological question. Moreover, to define beliefs, expectations as availability to an 'affecting' that both creates events and is created by them, may also help us to overcome the great dividing-up that results from the 'will to make science'. With the notion of 'availability' the signs that mark the world and that mark the subject are redistributed in a new way. Both are active and both are transformed by the availability of the other. Both are articulated by what the other 'makes him/her make'. This is, in my opinion, the most interesting characteristic of the practices that may be defined as practices of domestication, the practices that allow themselves to be pervaded by humans: they are practices that create and transform through the miracle of attunement.

This miracle of attunement, be it between Hans and his questioners, between horses and their riders, or between rats and their student-experimenters, radically changes the question we may address to the body. If we are forced to give up on the issue of 'what a body is', our access leads us to question it in quite a different manner. All our examples raise the same problem: what the body makes (us) (others) do. And as all our examples suggest, this body that 'makes one make' is primarily articulated by affects. All these events we described, rats handled with cautious hands, motor discharges, tensions and attention, desires, embodied interests, bodies learning to feel like a horse, now call for a theory of affected and affecting bodies. That is, a theory of emotions.

\section{How Do You Feel about Theories?}

If we call here for a theory of affecting and affected bodies, or in a word, a theory of emotions, let us not forget what we have learned up to now. If we want to explore how these experiences with rats or horses are constructed, if we want to gain an access that gives the chance for many more entities to be active, we need a theory that prevents us from deciding too quickly what is cause and what is effect, what affects and what is affected. James's theory of emotions provides a good means to build this undetermined site: the emotions become, in his theory, an undetermined experience that split up the world, minds and bodies in a radically different way; an experience which discloses perplexity. James's emotional experience discloses perplexity in that it enables us to overcome the distribution between causes and effects, between bodies and minds, world and bodies, world and consciousness. First, concerning the body itself, James reminds us of its peculiarity: it resides in a strange ambiguous sphere of being; our body belongs 
sometimes to the world of objects, to the world out there, it belongs sometimes to the world of subjects, the world inside. In some cases, the body is the object to know; in others, it comes to be the knowing subject; sometimes part of nature, of the objective world, sometimes linked to the mind and to subjective events.

James's theory of emotions discloses the same kind of ambiguity. According to James, emotional experience belongs to that strange sphere of experiences where neither world, nor body, nor consciousness can be clearly separated, distributed.

Emotional experience, in other words, is an experience that makes us hesitate. Each of the events that composes it may not be firmly divided up, may hardly be defined as unequivocal cause or unequivocal effect, may not be definitively said to belong to the world, the body or the mind. Each of the emotional experiences can remain equivocal: they appear ambiguous, insofar as they seem neither quite inner nor quite outer, 'as if a diremption (sic) had begun but had not made itself complete . . . sometimes the adjective wanders as if uncertain where to fix itself' (James, 1890: 35-6). Should we talk about seductive visions or of visions of seductive things? Of feelings of anger or of angry feelings? Of good impulses or impulses toward the good? ${ }^{15}$ Both, James says, both are in the mind and in the things.

Indeed, most of our theories, whatever the classifications they choose, classify emotions as if they were not ambiguous or equivocal - or, even more, classify them in order to make them less equivocal - and may be characterized as operating the translocation of experiences in one world or in the other. For some of them, I laugh because the joke was funny, I am scared because the world is terrifying, while for others the joke is funny because I laugh, the world is terrifying because I am scared. Each of these theories, aiming to define what an emotion is, distributes the signs in discrete groups, on the one hand assuming they explain how the world affects the mind, and on the other hand, how the mind affects or construes the world.

Of course, the ambiguity James wants to produce or to preserve, does not appear at first glance. When he defines emotion 'as nothing but the feeling of a bodily state, and [which] has a purely bodily cause' (1890: 459) - we do not cry because we are sad, we are sad because we cry - we often misconstrue the proposition as a radically materialistic conception. Some detractors complained about the loss of the world (empiricists, realists and, even more, social theoreticians); ${ }^{16}$ while others bemoaned the loss of consciousness (Sartre, 1995, is an example). Such contradictory reproaches provide the best evidence that it was not the absence of the world or of consciousness that was problematic, but rather their mode of presence, their way of being present, hesitating, perplexed, undecided. 
What has been the most misconstrued was James's aim itself: it was not to define what is felt but what makes feel, it was not to define a passive affected being, but rather a being that both produces emotions and is produced by them. ${ }^{17}$ An emotion is not what is felt but what makes us feel.

And as to Sartre's question 'Where is the mind?', James would answer that the mind is exactly where it should be, in the skin, in the breath, in all these 'small corners of physical nature our bodies occupy' (James, 1958a: 151). And to the social theoretician's question 'Where is the world?' he would answer: the world is at the same place, exactly, and emotion arises at the intersection of the process. Maybe he would even go as far as to say that emotion makes the intersection of the process, and it makes it last. 'Our body itself', he writes, 'is the palmary instance of the ambiguous. Sometimes I treat my body purely as a part of outer nature. Sometimes, again, I think of it as "mine", I sort it with the "me", and then certain local changes and determinations in it pass for spiritual happenings' (1958a: 153). Ambiguous experiences, ambiguous bodies, experiences making bodies and bodies making experiences; signs that wander, hesitate to fix themselves: we produce emotion, and it produces us. The inner world is outside, the outer world passes inside, sometimes in the guise of wine that makes us joyous, or maybe we should also say, in the form of a wine that our body makes joyous:

We see that joyous thoughts dilate our blood-vessels, and that a suitable quantity of wine, because it dilates the vessels, also disposes us to joyous thoughts. If both the jest and the wine work together, they supplement each other in producing the emotional effect, and our demands on the jest are the more modest in proportion as the wine takes upon itself a large part of the task. (1958a: 462)

This is an experience of 'making available' that is described here, an experience by which both the body and what affects it produce each other. Each of the events (wine, thoughts, vessels, jests) creates an occasion for the others: should we say that the wine made us happy or that we made the wine joyous? Each one authorizes the others and is authorized by the others. The world disposes us to feel, and our body makes the world available. Our feelings dispose our bodies, our bodies dispose our feelings. ${ }^{18}$

We may now understand a little better what had been lost in Clever Hans's story when Rosenthal reinterpreted it. Rosenthal forced us to choose between scientific truth and interest. If we follow him, we will lose one of the entry points that enable us to explore how bodies may be moved by interests; how interests may be embodied and transformed into affects; and how these embodied affectinterests, in scientific practices, transform both the scientific itself and the active object (inducer) of his interest.

What was lost in Rosenthal's project is, however, fortunately still at work in 
some practices. This is probably not by chance; we may find the most interesting examples in the practice of ethology. If we follow carefully how some of these scientists create access to the creatures they study, the way they are moved by their subjects of interest, the way they give them a chance to be interesting and to articulate other things, we notice that the signs that define subject and object, what talks and what is talked about, subjectivity and objectivity, are redistributed in a new manner.

\section{New Distributions: Lorenz and the 'Becoming Jackdaw'}

In the beginning of the spring of 1928, therefore the first spring of my 'fourteen' born in 1927, Green-Yellow, the despot of that time, got engaged to Yellow-Red, the prettiest among the available young persons. She was the one I would have chosen also. (Lorenz, 1985: 90)

Don't we have here a perfect example of anthropomorphism? What should we call this: empathy, projection? Animal becoming human, and telling a human story, with human words?

Let us not go too fast, let us ease off again and allow a redistribution of signs. The young female jackdaw Lorenz would have chosen is not an anthropomorphous jackdaw. First, we may rather suggest the opposite; that it is Lorenz who has been metamorphosed: he became a jackdaw. Certainly, to consider it in this way allows us to understand how he could have this beautiful idea of ascribing to a non-human a competence we have always believed to be human: the jackdaw is zoomorphic, it sees others as other 'selves'. And we may suggest that Lorenz's jackdaw could gain this competence because Lorenz has been able to zoomorphize himself. But to say that Lorenz became a jackdaw is still going too fast, it is still distributing according to simple analogies: that proposition, for example, could too easily refer to empathy. And to refer to empathy is not to resist the distribution, it is to perform it once more. Empathy, as explanation, does not disclose how each of them, Lorenz and the jackdaw, has been articulated into the relationship. Certainly, empathy transforms the subject (the one who feels empathy) but this transformation is a very local one as long as it does not really give his object the chance to be activated as subject, the subject feeling empathy remaining the only subject of the whole thing. While pretending to be inhabited (or locally transformed) by the other, the empathic in fact 'squats' in the other. Empathy allows us to talk about what it is to be (like) the other, but does not raise the question 'what it is to be "with" the other'. Empathy is more like 'filling up one self' than taking into account the attunement. ${ }^{19}$

The story that tells how Lorenz met his first jackdaw may help us to construe another interpretation. 
When I bought it in a pet-shop, it was for reasons that have nothing to do with scientific reasons: I felt, all of a sudden, the craving to fill this big red and yellow beak the bird was keeping wide open toward me with good foods. (1985: 63)

Certainly, Lorenz, while being affected by the begging of the bird, metamorphosed himself. He was 'imprinted' by the begging: what was a specific signal, a specific bird's pattern that induces a parent to feed its offspring, this time worked on him. The begging jackdaw offered Lorenz a new identity; Lorenz's passion took then the form of a bird's instinct. And therefore, Lorenz acted as if he belonged to that species and he did that in such a convincing manner that the jackdaw got caught up in the game, and began, after a while, to see Lorenz as a member of the species which needed to be fed. However, the story is still not comprehensive enough. This jackdaw in its turn, Lorenz explains, incessantly tried to feed him, and did not rest until it could fill Lorenz's mouth with fresh worms and other good food. And, Lorenz says, when it was feeling abandoned, it shouted out the call by which the juvenile birds call their parents back.

When the little goose Marina hatched out, Lorenz decided to keep her a few hours before confiding her to the domesticated goose's care, so she could recover. He spent these few hours observing her. But as soon as the little goose was given to the care of the old one, she refused to stay, and addressed to Lorenz a desperate 'abandoned call'. Lorenz tried, but could not convince her not to follow him. Then, he says, I behaved exactly as if I had adopted her, pretending to ignore that, in fact, it was she who had adopted me. For the whole day, and the coming days and months, Lorenz played the role of a good mother goose.

There are, Lorenz explains, two kinds of field ethologists: the hunter (like Tinbergen), and the cattle-breeder, like himself. The hunter follows the animals in their own field, and observes them. The cattle-breeder keeps them with him, and tries to provide them with the most natural conditions. What Lorenz is trying to build is indeed an ethos, a goose's ethos, but it is still more an ethos pervaded with humans, an ethos for which the 'natural conditions' are, in an undetermined manner, of the nature of the animal and of the nature of the one who questions him, an ethos where 'natural condition' never means neutral condition. What Lorenz constructs with his goose (or his jackdaw) is the ethos of domestication.

This device clearly discloses itself as a 'domesticating device' when Lorenz uses his own body as a tool for knowing, as a tool for asking questions, as a means to create a relation that provides new knowledge: how does a goose become attached to its mother? Lorenz takes the mother's place, and becomes all at once a variable of the experiment. He then discloses the 'critical period', and the way the 'following answer' is both innate for its pattern and acquired in 
regard to its object. The device, the goose and Lorenz have therefore constructed the practical conditions that allow each of them to bring into existence new possibilities, new availabilities: the goose acquires a flexible behaviour and surprises Lorenz by adopting him. Lorenz becomes ready to become a goose's mother and may therefore add to his scientific repertoire new questions about imprinting, new questions about attachment, new ways of collecting data, new competences and new ways of carrying out his scientific practice.

The experimenter, far from keeping himself in the background, involves himself: he involves his body, he involves his knowledge, his responsibility and his future. The practice of knowing has become a practice of caring. And because he cares for his young goose, he learns what, in a world inhabited by humans and geese, may produce relations.

He involves his own responsibility because he will have to fulfil the goose's needs, ${ }^{20}$ to be a ' good mother' for it, to care for it, to walk like it, to talk like it, to answer its calls, to understand when it is scared. Lorenz and his goose, in a relation of taming, in a relation that changes both identities, have domesticated one another. ${ }^{21}$ Lorenz gave his birds the opportunity to behave like humans, as much as his birds gave him the opportunity to behave like a bird. They both created new articulations, which authorized them to talk (or to make the other talk) differently.

Therefore, when Lorenz talks about goose's love as very similar to human love, we are not going to claim that his goose is anthropomorphous, nor that humans are 'goosomorphous'. ${ }^{22}$ In some sense, Lorenz, producing a goose body, may be said to be 'goosomorphous'. It is because he could love in a goose's world, because he could produce an affected body (remember the horse's rider performing horse's movements) that he could compare its love to our own (which allows him to suggest that it is precisely in their manner of falling in love that many birds and mammals behave like humans). Of course, in some sense we could also say that Lorenz talking about goose's love is anthropomorphic. He uses human words, but this anthropomorphism is something more than a simple attribution: as long as his body is producing and being produced by a new identity, this experience is a new way of being human, which adds new identities. Therefore, being anthropomorphic means here to add new definitions to what it is to be a human being. Lorenz adds new meanings to love, and new identities that provide these new meanings. ${ }^{23}$ This practice of domestication is, once more, an anthropo-zoo-genetic practice.

But this experience is not only an anthropomorphic or a zoomorphic experience. The experience of loving is first of all a shared experience (which does not infer that it is a symmetrical experience, as long as Lorenz does not expect the 
goose or the jackdaw to love him the same way he loves them). Even more, the whole experience is a shared experience, an experience of being 'with'. Rather than saying that Lorenz became a jackdaw, I suggest that Lorenz became a 'jackdaw-with-human' as much as the jackdaw became in some ways a 'humanwith-jackdaw'; Lorenz did not become a goose, as we asserted too quickly, he became 'with a goose-with a human'.

This is a new articulation of 'with-ness', an undetermined articulation of 'being with' that makes us suggest that, finally, when Lorenz talks of love, he does not articulate human words. The opposite: Lorenz is articulated by the setting he created. The setting is articulating new ways of talking, new ways of being human with non-human, human with goose, goose with human. ${ }^{24}$

This experience by which Lorenz constructs a 'being with' sheds light on one of the ways bodies and worlds articulate each other: it is a particular mode of 'disposing' both body and world. Lorenz produces a goose's body to allow a goose's world to affect him (and also to allow a human's world to affect a goose). He learns to be affected.

While asking what matters in a goose's or in a jackdaw's world, in making his own body articulate this question the way he does, Lorenz not only raises the question from the point of view of the one to whom the question is addressed. He does more than that: he activates this point of view, and therefore he activates his object as a subject, a subject of passion, a subject producing passions; a subject of questions, a subject producing questions. Lorenz not only arouses a subject from the point of view his body is constructing, but he is himself activated by the one he gave existence to. He is activated as a subject both creating and created by passions. What passion means refers neither to some parasitic supplement nor to some sweet story of love: it means to make an effort to become interested, to immerse oneself in the multitude of problems presented by a jackdaw or a goose, to grow, to experience the following of a mother, the fear of strangers. ${ }^{25}$ It means to care. What passions teach Lorenz, both his own and the ones he gives the opportunity to exist, is that learning how to address the creatures being studied is not the result of scientific theoretical understanding, it is the condition of this understanding.

To 'de-passion' knowledge does not give us a more objective world, it just gives us a world 'without us'; and therefore, without 'them' - lines are traced so fast. And as long as this world appears as a world 'we don't care for', it also becomes an impoverished world, a world of minds without bodies, of bodies without minds, bodies without hearts, expectations, interests, a world of enthusiastic automata observing strange and mute creatures; in other words, a poorly articulated (and poorly articulating) world. 
What really exists is not things made but things in the making. But put yourself in the making by a stroke of intuitive sympathy with the thing and . . . you are no longer troubled with the question which of them is the more absolutely true. (James, 1958a: 263-4)

\section{Notes}

1. Pfungst writes (1998: 241):

The interrelation existing between ideas having a high degree of affective coloring and the musculature of the body (which is brought to light in this process), is by no means a novel fact for us. Nevertheless, it is possible that this case may be of no small value, on account of the great difficulties which are usually met in the attempt to establish experimentally the more delicate details in this field.

2. See the beautiful analysis of Eileen Crist (1997: 41), with whom I sometimes disagree in this article.

3. And therefore, the emotional investment of the professional experimenter would be in collecting the most accurate data possible (Rosenthal, 1966: 344). Clearly, the data are given, per se, and wait to be collected by an enthusiastic automaton.

4. For a similar way of giving the chance of a new distribution, see the analysis of Milgram's experience by Isabelle Stengers (1993), who offers the means to think about a distribution that multiplies, that complicates the ontology of beings in relation.

5. Of course we actually (and almost unduly, but it is for the sake of the world) completely reverse Rosenthal's aim.

6. And we may see, therefore, the pervading effect of authority: to have the authority to authorize is to make the one who is authorized gain authority, and thereby, to be entitled to authorize, in his/her turn, someone else (Rosenthal authorizes the student, the student the rat, my analysis authorizes Rosenthal and vice versa, further analysis, and so on).

7. This note is for those who wonder if Rosenthal fulfils my own expectations: of course, he does. I propose to him a new mode of existence, and I do it because I will never define my own practice as a collection of data, but as a set of propositions that offer new identities.

8. This is not a simple matter of theoretical interest. An intelligent animal may provide an opportunity for the 'becoming' intelligent of the ethologist who observes it. Zahavi's extraordinary Middle Eastern birds, the babblers, show good evidence of this (Despret, 1996). To consider ethological practices as anthropo-zoo-genetic practices, also producing humanity, constitutes therefore a practical or a pragmatic interest.

9. 'God's Heart and the Stuff of Life' Conference (1996). This is, in fact, what Rosenthal blames the scientists, and humans and non-humans for producing in the laboratory and in research: none of them show sufficient 'good' indifference.

10. Harlow was a famous primatologist who aimed to disclose the vital necessity of attachment in monkeys. For that purpose, he built a device that dramatically prevents newborn monkeys from establishing links with mother and peers. Newborn monkeys were separated from their mother and peers, and isolated for months in a little cage. The dramatic effects of separation (pathological and selfdestructive behaviour, despair and very deep depression), according to Harlow, clearly showed that attachment is a primal need. All the devices were built to evaluate different situations confirming the terrible effect of separation (already well acknowledged by psychiatrists since the Second World War) (Harlow, 1964).

11. Resistance or 'récalcitrance', see Stengers (1996-7), and Latour's comments (1997).

12. Rosenthal quotes this comment to show that the experimenters were not aware that their rats were not specially bred. 
13. Of course, T-mazes are probably not the best signs that 'make a world' for a white-coated rat (but who knows, as long as they are created by and for laboratories, how to define these good signs unless we give them the chance to help us to learn this). The problem is still more obvious (and obviously more complicated) when we raise the question of the good ethos to give to a rat especially bred in order to produce rats that like alcohol, for example. But we can assume that it makes sense for a rat to be handled, encouraged, caressed, fed.

14. For a similar analysis in the case of human psychology, see my previous work about emotions (Despret, 2004).

15. Or, to put it in our own words, do we laugh because the joke is funny, or is the joke funny because we laughed?

16. See, for example Schachter and Singer (1962).

17. For example, he talks about dispositions that we cultivate (James, 1890: 463).

18. Actors, James says, all know this simple fact: if we want to feel an emotion, we can dispose our body to produce it, and we will feel it. The psychologist Fechner, James explains, says almost the same thing of himself:

. . . when I walk behind someone whom I don't know, and imitate as accurately as possible his gait and carriage, I get the most curious impression of feeling as the person himself must feel. To go tripping and mincing after the fashions of a young woman puts one, so to speak, in a feminine mood of mind. (1890: 464)

19. Bergson's concept of sympathy, since it means some sort of 'articulated rhythm of activity' avoids the impoverishment that empathy brings with it.

20. With the jackdaws, Lorenz takes into account that to protect them requires attention: to call them back when they get lost, for example. When the colony almost disappeared, and leaving only one old female, he adopted four juveniles so she would not be too lonely, and took care in helping her to adopt them.

21. Certainly, the term 'domestication' may invoke a connotation of subordination. But I take for granted here that the contrast I tried to build between 'to make available' and 'to be docile' allows us to refer to the situations where both Lorenz and his goose are domesticating each other. We should also pay attention to the fact that if domestication refers univocally to situations of control or mastering, it may be so because we still do not have a good theory of attachment (see about this point, the work of Latour).

22. Anseromorphous would be the right term here (anserine = of, like a goose).

23. See Latour's comment on Thelma Rowel's work in terms of 'giving a chance' to the animals she questions (2000).

24. In Lapoujade's words (1997: 39; commenting on James) it would become: this is not Lorenz who produces interpretation, it is rather the opposite, Lorenz produces himself in the interpretations; moreover, 'he is an interpretation, an interpretation of his bodily affections'. Lorenz's passion as well as the goose's passion is not what is felt, it is what makes them feel. Lorenz produces a goose's or a jackdaw's body, and is, all at once, produced by this experience.

25. This is the contrast that should be drawn with Clever Hans. The case is interesting only as so far as we give up on the questions about the horse's conceptual intelligence.

\section{References}

Crist, E. (1997) 'From Questions to Stimuli, from Answers to Reactions: The Case of Clever Hans', Semiotica 113(1-2): 1-42.

Despret, V. (1996) Naissance d'une théorie éthologique: la danse du cratérope écaillé. Paris: Synthélabo, Les Empêcheurs de penser en rond. 
Despret, V. (2004) Our Emotional Makeup: Ethnopsychology and Selfhood. New York: Other Press.

Harlow, H. (1964) 'An Experimentalist Views the Emotion', pp. 254-61 in P. Knapp (ed.) Expressions of the Emotion in Man. New York: International University Press.

James, W. (1890) Principles of Psychology, vol. II. New York: Henry Holt.

James, W. (1958a) Essays in Radical Empiricism. New York: Longmans Green.

James, W. (1958b) A Pluralistic Universe. New York: Longmans Green.

Lapoujade, D. (1997) William James: empirisme et pragmatisme. Paris: PUF.

Latour, B. (1997) 'Des sujets récalcitrants', La Recherche 301: 88.

Latour, B. (2000) 'A Well Articulated Primatology: Reflections of a Fellow-traveler', in S. Strum and L. Fedigan (eds) Primate Encounters. Chicago: University of Chicago Press.

Lorenz, K. (1985) Il parlait avec les mammiferes, les oiseaux et les poissons, trans. B. Villeneuve. Paris: Flammarion.

Pfungst O. (1998) Clever Hans (The Horse of Mr Von Osten): A Contribution to Experimental Animal and Human Psychology, trans from German by C. Rahn. Bristol, Tokyo: Thoemmes Press and Maruzen Co. (First published 1911.)

Rosenthal, R. (1966) Experimenter Effects in Behavioral Research. New York: Appelton.

Sartre, J.-P. (1995) Esquisse d'une théorie des émotions. Paris: Herman. (First published 1938.)

Schachter, S. and J. Singer (1962) 'Cognitive, Social and Physiological Determinants of Emotional State', Psychological Review 69(5): 379-99.

Stengers, I. (1993) L'Invention des sciences modernes. Paris: La Découverte.

Stengers, I. (1996-7) Cosmopolitiques, 7 vols. Paris: La Découverte/Synthélabo, Les Empêcheurs de penser en rond.

Vinciane Despret is a philosopher and psychologist. She teaches Philosophy of Psychology at the University of Liège and Ethology of Animal Societies at the University of Brussels. She has published on ethology (Naissance d'une théorie éthologique: la danse du cratérope écaillé and Quand le loup habitera avec l'agneau) and on human and animal psychology (Our Emotional Makeup: Ethnopsychology and Selfhood, Other Press; and Hans, le cheval qui savait compter). 